\title{
Educational Utility of Social Media for Laparoscopic Surgery in India: A Cross-Sectional Survey of Popular Indian Communities on Facebook
}

\author{
Deepa Rajan' \\ Vinod G Pillai ${ }^{2}$ \\ Patsy Varghese' \\ 'Department of Obstetrics and \\ Gynecology, Believers Church Medical \\ College Hospital, Thiruvalla, Kerala, India; \\ ${ }^{2}$ Department of Surgery, Believers \\ Church Medical College Hospital, \\ Thiruvalla, Kerala, India
}

\begin{abstract}
Introduction: The Covid pandemic and social distancing has adversely impacted the conventional apprenticeship method of postgraduate training in laparoscopic surgery. Social media may be a useful adjunct for laparoscopic training, but its utility in developing countries like India has not been studied carefully. This paper describes an observational, cross-sectional study on the educational utility of Facebook groups based in India and which focus on laparoscopic gynecologic surgery.
\end{abstract}

Methods: The most popular Facebook groups involving Indians and focusing on laparoscopic gynecology were identified using appropriate search terms as well as inclusion and exclusion criteria. Demographic data related to the groups, the authors of posts as well as descriptive statistics of all the posts during the study period were collected and appropriate statistical analysis was performed.

Results: All the groups in this study were large and growing steadily. Posts related to laparoscopy were more likely to be videos, dealing with operative techniques and having educational value for postgraduate residents ( $\mathrm{p}$ value $<0.001$ ) compared to posts unrelated to laparoscopic surgery. The majority of posts $(88.2 \%)$ presented original content created by group members rather than material shared from other sources. Members preferred to share laparoscopic content using links to their personal YouTube channels rather than using institutional YouTube channels, dedicated websites for laparoscopic surgery or direct posts on Facebook. Group members liked educational content and laparoscopic surgery-related content significantly more than other content. Only $16.7 \%$ of the laparoscopic surgeons could be identified to be working in academic institutes.

Conclusion: Social media for medical education has inherent advantages and disadvantages. This article provides objective data regarding its utilisation in a developing country in the midst of the Covid pandemic, and provides a guide for further research and development of innovative teaching methods.

Keywords: online learning, distance learning, surgical education, laparoscopic gynecology, Covid pandemic, social media

\section{Introduction}

Surgical residents traditionally learn laparoscopic surgery by following the apprenticeship model. An acceptable level of proficiency is attained by observing, assisting and operating a significant number of cases to overcome the learning curve. However, the requisite volumes of surgical cases may not be available in many institutes because of factors such as reduction in elective case volume, reduction in opportunities to "scrub up" for cases, increased number of trainees, etc., especially
Correspondence: Vinod G Pillai

Department of Surgery, Believers Church Medical College Hospital, Thiruvalla,

Kerala, 689103, India

$\mathrm{Tel} / \mathrm{Fax}+914693503100$

Email drvinodpillai@gmail.com 
due to social distancing norms introduced during the COVID-19 pandemic. Apart from the experience inside the operation theatre, the conventional resources for learning operative surgery include textbooks, atlases and journals. However, it is challenging to learn many aspects of laparoscopic surgery from printed books. Other resources include medical conferences and operative workshops, but factors such as cost, time and travel restrictions, have limited their utilisation at present.

Since laparoscopic surgery is easy to record and share through electronic means, it may be easier to adapt laparoscopy training to the new circumstances. ${ }^{1}$ Video sharing sites (like YouTube $\odot$ and Vimeo $\odot$ ) and websites maintained by dedicated groups (like www.websurg.com, www. aischannel.com) have greatly benefited laparoscopic surgeons worldwide. ${ }^{2}$ However from the perspective of medical education, video sharing sites are not optimised for assessing the safety and usefulness of the video or for discussion among peers. On the other hand, social media platforms, such as Facebook $($, LinkedIn $($, Instagram $($, Twitter@, etc., enable easy interaction and facilitate sharing of videos, updates, news and research articles. Hence, there has been active interest in developing learning platforms on social media. ${ }^{3}$

The role of social media in surgical education has been studied in developed countries, ${ }^{4}$ but there is limited research on how Indian surgeons are utilising social media to communicate and teach laparoscopic skills. Although trainees in developing countries like India can potentially access overseas based resources, these may not be suitable for medical education in India because of differences in the structure of training programs, spectrum of cases, hospital protocols, availability of universal medical insurance and availability of expensive laparoscopic equipment like energy sealing devices and staplers for anastomosis. Hence, we decided to investigate the current status of social media communities which are based in India, from the perspective of educational utility. Important objectives included an assessment of the relevant communities in the field of laparoscopic surgery, an assessment of the nature of posts in these communities and their relevance for postgraduate medical education in India. Moreover, the characteristics of the laparoscopic surgeons active across these groups was also sought to be studied.

\section{Materials and Methods}

Popular social media platforms, such as Facebook, Twitter, Instagram and LinkedIn, were initially surveyed. VKC, WeChat $\odot$, WhatsApp $\odot$ and Telegram $\odot$ were not surveyed because of reasons such as low user base in India and limitations in identifying the country of origin of groups related to laparoscopic surgery. Facebook is the most popular social media platform in India, ${ }^{5}$ and it had far more groups fulfilling these criteria compared to other social media platforms. Hence, we decided to focus on communities on Facebook, known as Facebook Groups.

On initial survey, some popular Facebook groups were found to be related to a subspeciality (eg, colorectal surgery, bariatric surgery, hepatobiliary surgery, etc.) and hence of limited utility from the perspective of postgraduate medical education. Some popular general surgery groups had a relatively low proportion of content on laparoscopic surgery and the data were not amenable for meaningful analysis. On the other hand, we found multiple groups in the specialty of obstetrics and gynecology, which were focused on laparoscopic gynecology procedures. The proportion of laparoscopic content on these groups was high and the described procedures were relevant to postgraduate residents in obstetrics and gynecology. Hence, the target population for this study included all Facebook groups which were predominantly Indian and focusing on laparoscopic gynecology.

This observational study follows the Strengthening the Reporting of Observational Studies in Epidemiology (STROBE) guidelines for cross-sectional studies. ${ }^{6}$ The study design and analysis plan were prepared in June 2020 and approval was obtained from the Institutional Research Committee. Informed consent was not needed since no patients were identified, no interventions were performed for this study and no patient data was collected. Special attention was paid to privacy issues. The rules of each Facebook group in this study were examined to avoid infringements. Appropriate code names or numbers were allotted to every post, person and group after data collection and only anonymised data was used for statistical analysis and manuscript preparation. The Institutional Ethics Committee of Believers Church Medical College Hospital, Thiruvalla, India, considered and approved the study (IEC Study no. IEC/2021/196).

Data collection was done after logging into the authors' Facebook accounts using Chrome browser on their individual laptops, after confirming that the IP location for every browsing session was within India. The data collection was done over 3 days in July 2020, five weeks after the last post included in this study was published on Facebook, in order to avoid bias related to timing of data collection. 
The following terms were searched on the Facebook Groups webpage to identify social media communities related to gynecology and laparoscopy: gynaecology, gynaecologic, gynecology, gynecologic, gynecologic endoscopy, hysterectomy, laparoscopy, laparoscopic, laparoscopic gynecology, laparoscopic gynaecology, TLH, laparoscopic hysterectomy, minimal access surgery, minimally invasive gynecology, minimally invasive gynaecology, obgyn, obgyn discussion group, obstetrics and gynecology, obstetrics and gynaecology. The groups thus identified were included in the study if they met both the following criteria: (1) more than $50 \%$ of the posts over the previous two months were by Indians and (2) more than $50 \%$ of the group administrators and moderators were residing in India or more than $50 \%$ of the members could be identified as residing in India.

Groups with less than ten posts per month, those with marginal activity related to laparoscopic gynecology and private groups which did not respond to the authors' request to join $(\mathrm{n}=2)$ were excluded.

We found 21 groups after applying the inclusion and exclusion criteria. The groups were ranked by the number of members and number of posts per month. Since the sampling frame was small and since the number of posts were not normally distributed across the groups, sample size was not formally calculated, and a cross-sectional survey of the ten most popular groups was carried out. The main Facebook page, membership details, membership criteria, administrator and moderator details, aims and rules of the group, privacy settings, and posts of each group were studied. The demographic data of each group was collected in a Microsoft ${ }^{\circledR}$ Excel $^{\circledR} 2016$ spreadsheet (Table 1). Descriptive and exploratory data analyses were performed using SAS $^{\circledR}$ University Edition software (Copyright (C) 2012-2020, SAS Institute Inc., Cary, NC, USA). Descriptive statistics were presented as frequencies (n) and percentages (\%) for categorical variables and mean or median (standard deviation, range) for continuous and ordinal variables. Student's $t$-test for independent ordinal samples and $z$ score test for proportions for independent nominal samples were performed (two-tailed test, with significance level 0.05 ) to check whether the null hypothesis that there is no significant difference between laparoscopic and nonlaparoscopic posts could be accepted or rejected.

All the posts published in these groups over a period of fifteen days in June 2020 were included for analysis. Each post was given a unique code number and its characteristics were analysed. Each post was characterised
Table I Descriptive Statistics of the Ten Facebook Groups

\begin{tabular}{|c|c|c|}
\hline & & $\begin{array}{c}\text { Number of } \\
\text { Groups }\end{array}$ \\
\hline Number of members & $\begin{array}{l}>10,000 \\
5000- \\
10,000 \\
1000-5000\end{array}$ & $\begin{array}{l}2 \\
3 \\
5\end{array}$ \\
\hline $\begin{array}{l}\text { Related to medical society or } \\
\text { academic institute }\end{array}$ & & 0 \\
\hline Age of group & $\begin{array}{l}<\mathrm{I} \text { year } \\
\mathrm{I}-3 \text { years } \\
3-5 \text { years }\end{array}$ & $\begin{array}{l}2 \\
1 \\
7\end{array}$ \\
\hline $\begin{array}{l}\text { New members joining in previous } \\
\text { week }\end{array}$ & $\begin{array}{l}<5 \\
5-15 \\
>15\end{array}$ & $\begin{array}{l}4 \\
3 \\
3\end{array}$ \\
\hline Number of posts in previous month & $\begin{array}{l}<10 \\
10-50 \\
50-100 \\
>100\end{array}$ & $\begin{array}{l}0 \\
3 \\
2 \\
5\end{array}$ \\
\hline $\begin{array}{l}\text { Group aims mention focus on } \\
\text { laparoscopic surgery }\end{array}$ & $\begin{array}{l}\text { Yes } \\
\text { No }\end{array}$ & $\begin{array}{l}8 \\
2\end{array}$ \\
\hline $\begin{array}{l}\text { Group aims mention focus on } \\
\text { educational activity }\end{array}$ & $\begin{array}{l}\text { Yes } \\
\text { No }\end{array}$ & $\begin{array}{c}10 \\
0\end{array}$ \\
\hline $\begin{array}{l}\text { Visibility of posts published in the } \\
\text { group }\end{array}$ & $\begin{array}{l}\text { Only } \\
\text { members } \\
\text { All } \\
\text { Facebook } \\
\text { users }\end{array}$ & $\begin{array}{l}6 \\
4\end{array}$ \\
\hline
\end{tabular}

according to the nature of the post (video, audio, text, link, image), the source of the post (originally posted on the group page or at another location on the internet), whether the content was created by the person who posted it or whether it is someone else's content being shared with attribution) and the content of the post (operative technique, lecture, related to surgical technology, related to research studies, post related to promotions or marketing, non-medical post, etc.) as described in Table 2. The number of likes, comments and authors' replies to comments were collected as shown in Table 3 . The educational utility of a post is subjective in nature and there are no validated scoring systems available for the purpose of this study. Hence, two of the authors (both experienced teachers in the department of obstetrics and gynecology) evaluated each post from the perspective of postgraduate medical education in Indian scenario and their results were checked for internal consistency using the kappa coefficient. ${ }^{7}$ 
Table 2 Descriptive Frequencies of Posts Published in Study Period (Percentage Composition Given in Brackets)

\begin{tabular}{|c|c|c|c|c|}
\hline & & $\begin{array}{l}\text { Laparoscopy Related } \\
\text { Posts }(n=189)\end{array}$ & $\begin{array}{l}\text { Non Laparoscopy Related } \\
\text { Posts }(n=202)\end{array}$ & p value \\
\hline Nature of post & $\begin{array}{l}\text { Video } \\
\text { Image } \\
\text { Link } \\
\text { Text } \\
\text { Audio }\end{array}$ & $\begin{array}{l}139(73.5) \\
29(15.4) \\
12(6.3) \\
9(4.8) \\
0(0)\end{array}$ & $\begin{array}{l}82(40.6) \\
49(24.3) \\
63(31.1) \\
4(2) \\
4(2)\end{array}$ & $\begin{array}{l}<0.0001 \\
0.0275 \\
<0.0001 \\
0.1252 \\
0.0518\end{array}$ \\
\hline Educational value & $\begin{array}{l}\text { Yes } \\
\text { No }\end{array}$ & $\begin{array}{l}155(39.6) \\
34(8.7)\end{array}$ & $\begin{array}{l}125(32) \\
77(19.7)\end{array}$ & $<0.0000$ \\
\hline Type of post & $\begin{array}{l}\text { Operative techniques } \\
\text { Surgical technology } \\
\text { Lectures } \\
\text { Research studies } \\
\text { Promotional posts } \\
\text { Related to medical field } \\
\text { Social/non-medical } \\
\text { Unclassified }\end{array}$ & $\begin{array}{l}123(65.1) \\
10(5.3) \\
24(12.7) \\
3(1.6) \\
28(14.8) \\
0 \\
0 \\
1(0.5)\end{array}$ & $\begin{array}{l}10(5) \\
2(1) \\
56(27.6) \\
0(0) \\
108(53.4) \\
9(4.5) \\
9(4.5) \\
8(4)\end{array}$ & $\begin{array}{l}<0.0001 \\
0.0042 \\
0.0002 \\
0.0723 \\
<0.0001 \\
0.0033 \\
0.0033 \\
<0.0001\end{array}$ \\
\hline Authorship of posts & $\begin{array}{l}\text { Posted own work } \\
\text { Shared work done by others }\end{array}$ & $\begin{array}{l}170(43.4) \\
19(4.9)\end{array}$ & $\begin{array}{l}175(44.8) \\
27(6.9)\end{array}$ & 0.3095 \\
\hline Source of posts & $\begin{array}{l}\text { Posted exclusively in the group } \\
\text { Post shared from another Facebook } \\
\text { group/person/page } \\
\text { Post shared from YouTube } \\
\text { Post shared from author related website } \\
\text { From other sources }\end{array}$ & $\begin{array}{l}28(14.8) \\
35(18.5) \\
98(51.9) \\
20(10.6) \\
8(4.2)\end{array}$ & $\begin{array}{l}66(32.8) \\
52(25.7) \\
35(17.3) \\
37(18.3) \\
12(5.9)\end{array}$ & $\begin{array}{l}<0.0001 \\
0.0861 \\
<0.0001 \\
0.0303 \\
0.4413\end{array}$ \\
\hline
\end{tabular}

The authors' details were obtained from their publicly available Facebook profiles wherever possible and basic demographic details of all authors whose posts were relevant to laparoscopic surgery are described in Table 4.

\section{Results}

All the Facebook Groups in our study had more than 1000 members, with the largest group having more than 50,000 members. None were affiliated to a gynecologic society or academic institute. Six groups opted to restrict visibility of the posts to members of the group whereas all Facebook users could see the content posted in the remaining groups. Eighty percent mentioned laparoscopic surgery as one of the core aims of the group. Only one group specifically prohibited promotional and marketing activities within the group. Membership was free for all groups and there were no strict criteria to assess whether new members are doctors in most groups. Seventy percent of these groups added more than 5 new members every week and there were more than 100 posts published every month in $50 \%$ of these groups (Table 1).

There were 391 posts distributed across the ten groups during the study period (Figure 1) and the descriptive data is presented in Table 2. The proportion of laparoscopyrelated posts ranged from $5.5 \%$ to $91 \%$ across the groups (overall 48.3\%). Posts related to laparoscopy were focused

Table 3 Comparative Analysis of Number of Likes Expressed for Facebook Posts in the Study

\begin{tabular}{|l|c|c|}
\hline & Mean \pm SD & P value \\
\hline Laparoscopic content & $4.5 \pm 2.7$ & 0.0022 \\
Non-laparoscopic content & $3.0 \pm 3.6$ & \\
\hline Educational content & $4.7 \pm 3$ & $<0.000 \mathrm{I}$ \\
Non-educational content & $2.2 \pm 3$ & \\
\hline Video based content & $4.6 \pm 3.1$ & $<0.000 \mathrm{I}$ \\
Non-video based content & $2.5 \pm 2.9$ & \\
\hline
\end{tabular}

Abbreviation: SD, standard deviation. 
Table 4 Demographic Characteristics of Indian Surgeons Who Posted Laparoscopy Related Content

\begin{tabular}{|c|c|c|}
\hline \multirow{4}{*}{$\begin{array}{l}\text { City of the author (if author is } \\
\text { Indian laparoscopic surgeon) } \\
(n=60)\end{array}$} & Tier I cities & $23(38.3 \%)$ \\
\hline & Tier 2 cities & 13 \\
\hline & Rest of India & 16 \\
\hline & $\begin{array}{l}\text { Unknown/ } \\
\text { abroad }\end{array}$ & 8 \\
\hline \multirow[t]{2}{*}{ Working in academic institute } & Yes & $10(16.7 \%)$ \\
\hline & $\begin{array}{l}\text { No/not } \\
\text { revealed }\end{array}$ & 50 \\
\hline $\begin{array}{l}\text { Source of post ( } n=147 \text { posts by } \\
\text { laparoscopic surgeons based in } \\
\text { India) }\end{array}$ & Original & $210(94.5 \%)$ \\
\hline
\end{tabular}

primarily on surgical techniques and instrumentation. Lectures and research articles pertaining to laparoscopy were more frequent compared to content related to other aspects of obstetrics and gynecology. Posts related to laparoscopy were much likelier to be videos in nature rather than slides or pure text-based posts $(p<0.0001)$. However, authors preferred to publish their videos on their YouTube channel or individual Facebook page and share the link on Facebook Groups, rather than directly posting their content in a group. A significant proportion also shared material from their own website. Both laparoscopic and non-laparoscopic content was overwhelmingly likely to be created by the author of the post. This is in stark contrast to the general content on social media where there is a preponderance of forwarded or shared posts.

The interrater reliability between the two assessors regarding the educational utility of the posts was found to be high (kappa coefficient 0.952, standard error 0.016, $95 \%$ confidence interval from 0.922 to 0.983 ). Posts related to laparoscopy were significantly more likely to be of educational utility compared to other posts ( $p$ $<0.0001)$. Majority of the non-laparoscopic posts $(53.4 \%)$ consisted of promotional activities for hospitals, medications, websites, courses, webinars, etc. General chats or news items comprised only $4.6 \%$ of the total posts.

The number of comments and likes were counted to assess the reaction to each post. Both showed an exponential frequency distribution. We found multiple instances of the same person writing multiple comments as part of a single explanation. Hence, it was difficult to carry out meaningful statistical analysis of the number of comments (overall mean 3.4 after log transformation to normal distribution). The number of likes were analysed further. The data were $\log$ transformed to derive the normal distribution curve, and mean and standard deviations were calculated. $t$-test for independent samples was performed. There was a significantly higher appreciation for posts which had content related to laparoscopy, for posts of an educational nature and for posts which were videos rather than texts or other media (Table 3 )

There were 60 authors in the ten groups who could be identified as Indian laparoscopic surgeons based on the

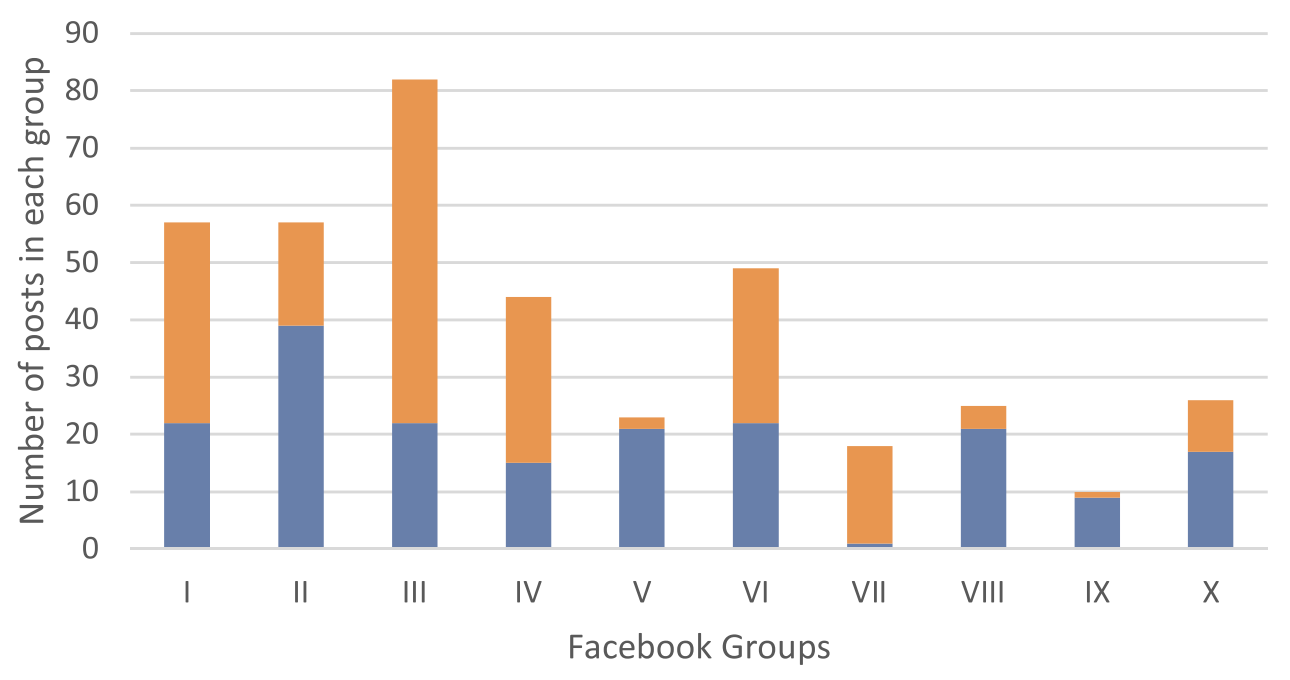

- Laparoscopy related content $\quad$ Other content

Figure I Distribution of posts and proportion of posts on laparoscopic surgery. 
content of their profiles and public posts on Facebook (Table 4). These authors were widely distributed across India, with $38 \%$ living in a tier 1 city. Only $16 \%$ could be identified to be working as faculty in a medical college. Ninety-five percent created and shared their own content rather than sharing content by someone else. Many authors preferred to share the same content in multiple groups, thus achieving higher visibility for their posts. The content in nine groups was shared by diverse people barring one group where the administrator posted more than $90 \%$ of the laparoscopic content.

\section{Discussion}

Studies have shown that more than $50 \%$ healthcare professionals use social media for accessing professional knowledge and have participated in online discussions. ${ }^{8}$ The current generation of medical students is very familiar with social media and more than $90 \%$ have been reported to have used it for learning. ${ }^{9}$ Social media tools have been associated with improved learner engagement, collaboration and knowledge in medical students. ${ }^{10}$

The importance of social media is likely to increase further in the future. Social media is an exponentially growing component of the internet, especially in the 18 to 30 years age group. Currently, 400 million Indians (and 4.14 billion people worldwide) are estimated to use a social media platform. Facebook is the most popular social media platform in India and it has the largest number of Facebook users in the world. ${ }^{5}$ But there is limited research on the relevance of social media for education of surgical residents in India. Our survey presents a snapshot of the current status of the most popular Facebook communities in the field of laparoscopic gynecology, from the perspective of an Indian user.

The search criteria used in our study returned predominantly Indian and South Asian groups and very few groups from Europe, the United States or East Asia. This may be due to the use of unspecified filters by Facebook to optimise search results by location. It may be difficult for a Facebook user to search for reputed international groups in his specialty. Consequently, surgical residents would be more likely to be a part of national groups rather than international groups.

Reputed surgical societies have realised the importance of social media for professional development and medical education. The American Association of Gynecologic Laparoscopists (AAGL) and International Society of Gynaecologic Endoscopy (ISGE) have a large membership on Facebook and are active on Twitter. The Society of Gastrointestinal and Endoscopic Surgeons (SAGES) based in the United States supports multiple Facebook groups related to laparoscopic specialties like bariatric surgery, colorectal surgery, foregut surgery, hepatobiliary surgery, etc., through its SAGES Masters Program for developing professional knowledge. ${ }^{11}$ However, the ten most popular groups in our study were not associated with any surgical society, medical journal or academic institute. Most of these groups were established more than 3 years ago and their membership was comparable if not larger than many international groups in the same specialty. Laparoscopy and education were recognised as core areas by almost all the groups in our study.

An analysis of the posts in our study revealed that a significant proportion of posts had educational value. While there were very few posts which were specifically aimed at medical residents, many videos on laparoscopic techniques described the procedure in detail and utilised graphics and voice commentary to make the post interesting and easy to understand. The significantly higher reactions generated by such posts in comparison to posts which did not have educational value may be considered a surrogate marker for the quality of the content. Previous studies have shown the potential of online videos as a training resource for laparoscopic surgery. ${ }^{12}$ The landmark LAP-VEGaS consensus guidelines have established criteria for assessing the educational quality of laparoscopic videos. ${ }^{13}$ However, validated scoring systems for comparison of educational videos based on these guidelines have not been developed yet.

The content on social media may not appear to be educational at first glance, since it does not fit the traditional pedagogical model of hierarchical learning. However, social media can enable the heutagogy model of learning where "free-agent learners" autonomously drive their own education with teachers as mentors. ${ }^{14}$ The learning theory of connectivism ${ }^{15}$ explains the advantages of distributing learning resources across a network, where network participants can autonomously access the resources and update themselves as per individual requirements. According to cognitive load theory, learner engagement is enhanced by utilising videos of less than 10 minutes duration and where asking questions is facilitated16 - the content on social media fits these criteria and it has additional advantages over traditional methods of learning. It is easy to initiate discussions with the author of the post as well as with other peers. Barriers to accessing resources 
involving cost (paywalls, subscriptions, membership of societies, travel and registration for conferences) and time (conflict with duty schedules, time taken to travel) are minimal with social media resources. The COVID-19 pandemic has also driven increased utilisation of learning resources which are accessible from home. ${ }^{17}$

The involvement of teachers is critical for the growth of social media as a learning platform. Our study revealed a very low proportion of posts whose authors could be confirmed to be teachers at medical colleges in India. Possible reasons for low teacher engagement could include lack of recording facilities for laparoscopic surgery, lack of good quality laparoscopic equipment and privacy issues. The current guidelines for career advancement in Indian medical colleges do not consider online education as a criterion. Since alternative metrics are being developed for online academic activities, ${ }^{18}$ these guidelines may change in the future and lead to increased involvement of medical college faculty in online education.

The easy access to online communities with high quality educational content may prove to be a significant resource for postgraduate training in India, in the context of limited resources and limited training opportunities in laparoscopy. We noted a few opportunities for innovation and development of medical education through social media. From the perspective of teachers and academic institutes, it is difficult to attract a large viewership for a new website or a new channel on YouTube focusing on surgical education. However, the power of social media can be harnessed by sharing good quality educational content across existing popular Facebook groups. From the perspective of surgical residents, there is an unmet need for good quality content on laparoscopic surgery which meets educational criteria and is approved for training by academic stakeholders. There is a need for communicating the level of complexity of a laparoscopic procedure, so that surgical residents can judge the usefulness of a post according to their progress on the learning curve.

Utilising social media for medical education has notable disadvantages as well. Sensational techniques and risky procedures may be more popular even though they may not follow standard guidelines. ${ }^{19}$ Perioperative factors and outcomes may not be revealed, leading to erroneous learning. The motivation for publishing laparoscopic material on social media may not always be aligned with educational values. Peers may not point out the shortcomings in a post for fear of causing offence to a colleague.
Combined with the lack of indexing, it is difficult to judge the quality of a post by its popularity alone. Privacy issues are also significant. A patient's details may be inadvertently revealed in a video or CT scan. An error in a post may be highlighted and shared elsewhere without the consent of the author.

This study has some limitations. There may be relevant closed groups on Facebook which did not turn up in our search results because of the restrictions kept by the group administrators. This cross-sectional study may have been biased due to undefined sample size and unknown selection bias. The data collection for this study was performed in the midst of the Covid pandemic, which may have impacted the characteristics of the posts and reactions to the posts.

\section{Conclusion}

Medical education on social media platforms can be complementary to traditional learning methods. The importance of social media is bound to increase further, considering its ubiquity and the limitations imposed on traditional learning methods by the COVID-19 pandemic. There is limited information on the applicability of learning methods via social media for laparoscopic surgery in India at present. Our study shows that educational content related to laparoscopy is appreciated by Indian surgeons on social media. Despite significant advantages like the egalitarian approach, ease of use, scope for active collaboration and self-directed learning and availability of vast amounts of online material, the utilisation of social media in India for postgraduate medical education is currently in the nascent stage.

The borderless nature of social media confers a significant first mover advantage for early adopters of social media. Currently, there is a big opportunity for stakeholders like postgraduate training programs, surgical societies and medical journals to harness the presence and scale of social media to direct academic development in India. Further research is needed to develop structured training programs and validated learning tools to quantify the impact of social media on medical education.

\section{Acknowledgments}

The authors acknowledge the valuable contribution of $\mathrm{Dr}$ Alice David, (MSc, PhD), Head of Medical Research (Epidemiology and Biostatistics), Believers Church Medical College Hospital, Kerala, India, for the statistical analysis in this paper. 


\section{Disclosure}

The authors report no conflicts of interest in this work.

\section{References}

1. Keller DS, Grossman RC, Winter DC. Choosing the new normal for surgical education using alternative platforms. Surg Oxf. 2020;38 (10):617-622. doi:10.1016/j.mpsur.2020.07.017

2. Rapp AK, Healy MG, Charlton ME, Keith JN, Rosenbaum ME, Kapadia MR. YouTube is the most frequently used educational video source for surgical preparation. J Surg Educ. 2016;73(6):1072-1076. doi:10.1016/j.jsurg.2016.04.024

3. Todorovic M, Coyne E, Gopalan V, Oh Y, Landowski L, Barton M. Twelve tips for using Facebook as a learning platform. Med Teach. 2020;1-13. doi:10.1080/0142159X.2020.1854708

4. Petrucci AM, Chand M, Wexner SD. Social media: changing the paradigm for surgical education. Clin Colon Rectal Surg. 2017;30 (4):244-251. doi:10.1055/s-0037-1604252

5. Statista. Internet users in the world; 2020. Available from: https:// www.statista.com/statistics/617136/digital-population-worldwide/. Accessed January 31, 2021.

6. Elm EV, Altman DG, Egger M, Pocock SJ, Gøtzsche PC, Vandenbroucke JP. Strengthening the reporting of observational studies in epidemiology (STROBE) statement: guidelines for reporting observational studies. BMJ. 2007;335(7624):806-808. doi:10.1136/ bmj.39335.541782.AD

7. Landis JR, Koch GG. The measurement of observer agreement for categorical data. Biometrics. 1977;33(1):159-174. doi:10.2307/ 2529310

8. Hamm MP, Chisholm A, Shulhan J, et al. Social media use by health care professionals and trainees: a scoping review. Acad Med. 2013;88 (9):1376-1383. doi:10.1097/ACM.0b013e31829eb91c

9. McGowan BS, Wasko M, Vartabedian BS, Miller RS, Freiherr DD, Abdolrasulnia M. Understanding the factors that influence the adoption and meaningful use of social media by physicians to share medical information. J Med Internet Res. 2012;14(5):e117. doi:10.2196/ jmir.2138
10. Wexner SD, Petrucci AM, Brady RR, Ennis-O'Connor M, Fitzgerald JE, Mayol J. Social media in colorectal surgery. Colorectal Dis. 2017;19(2):105-114. doi:10.1111/codi.13572

11. Jackson HT, Young MT, Rodriguez HA, Wright AS. SAGES foregut surgery masters program: a surgeon's social media resource for collaboration, education, and professional development. Surg Endosc. 2018;32(6):2800-2807. doi:10.1007/s00464-017-5983-1

12. Celentano V, Browning M, Hitchins C, Giglio MC, Coleman MG. Training value of laparoscopic colorectal videos on the World Wide Web: a pilot study on the educational quality of laparoscopic right hemicolectomy videos. Surg Endosc. 2017;31(11):4496-4504. doi:10.1007/s00464-017-5504-2

13. Celentano V, Smart N, McGrath J, et al. LAP-VEGaS practice guidelines for reporting of educational videos in laparoscopic surgery: a joint trainers and trainees consensus statement. Ann Surg. 2018;268 (6):920-926. doi:10.1097/SLA.0000000000002725

14. Filipe $\mathrm{H}$, Mack H. Teaching through social media. Ann Eye Sci. 2019;4:28. doi:10.21037/aes.2019.07.02

15. Goldie JGS. Connectivism: a knowledge learning theory for the digital age? Med Teach. 2016;38(10):1064-1069. doi:10.3109/ 0142159X.2016.1173661

16. Guo PJ, Kim J, Rubin R. How video production affects student engagement: an empirical study of MOOC videos. Proceedings of the first ACM conference on learning@ scale conference. L@S '14. Assoc Comput Machine. 2014;41-50. doi:10.1145/ 2556325.2566239

17. Docimo S, Jacob B, Seras K, Ghanem O. Closed Facebook groups and COVID-19: an evaluation of utilization prior to and during the pandemic. Surg Endosc. 2020. doi:10.1007/s00464-020-07971-0

18. Cabrera D, Roy D, Chisolm MS. Social media scholarship and alternative metrics for academic promotion and tenure. $\mathrm{J} \mathrm{Am} \mathrm{Coll}$ Radiol. 2018;15(1):135-141. doi:10.1016/j.jacr.2017.09.012

19. RodriguezHA, Young MT, JacksonHT, OelschlagerBK, Wright AS. VieJackson HT, Oelschlager BK, Wright AS. Viewer discretion advised: is YouTube a friend or foe in surgical education? Surg Endosc. 2018;32(4):1724-1728. doi:10.1007/s00464-017-5853-x
Advances in Medical Education and Practice

\section{Publish your work in this journal}

Advances in Medical Education and Practice is an international, peerreviewed, open access journal that aims to present and publish research on Medical Education covering medical, dental, nursing and allied health care professional education. The journal covers undergraduate education, postgraduate training and continuing medical education including emerging trends and innovative models linking education, research, and health care services. The manuscript management system is completely online and includes a very quick and fair peer-review system. Visit http://www.dovepress.com/testimonials.php to read real quotes from published authors. 